\title{
O TRIBUNAL DE CONTAS E O ENTENDIMENTO DO SUPREMO TRIBUNAL FEDERAL ACERCA DA LEGITIMIDADE PARA EXECUÇÃO JUDICIAL DAS DECISÕES À LUZ DO ARE 823.347 RG/MA
}

\author{
THE COURT OF AUDITORS AND THE SUPREME COURT OF UNDERSTANDING \\ ABOUT FEDERAL JUDICIAL ENTITLED TO IMPLEMENTATION OF DECISIONS \\ OF DECISIONS ARE 823.347 RG/MA
}

\author{
Priscila Ribeiro Nascimento ${ }^{1}$
}

\begin{abstract}
RESUMO
O presente trabalho teve por objetivo analisar o histórico e a questão da mudança do entendimento jurisprudencial recente, acerca da legitimidade ativa para execução judicial dos acórdãos proferidos pelos Tribunais de Contas, dentro da perspectiva histórica, constitucional, doutrinária e jurisprudencial acerca da decisão ARE 823.347 RGMA, quando do reconhecimento da repercussão geral, proferida pelo Supremo Tribunal Federal. Para chegar ao objetivo proposto, far-se-á uma analise de todo contexto histórico da criação do Tribunal de Contas até a promulgação da CRFB/88. Procurar-se-á entender quais são os critérios utilizados pelos Tribunais de Contas, para proferir as decisões (acórdãos) na prática cotidiana, relativa ao tema. Será levantada a natureza jurídica e eficácia dessas decisões, e sua aplicabilidade no contexto jurídico concreto. No final, será discutida a polêmica decorrente de diferentes interpretações conferidas a dispositivos constitucionais, e por fim, será feita analise a respeito da legitimidade ativa, se o Ministério Público possui legitimidade ativa ou até mesmo o próprio Tribunal de Contas poderia ter competência para executar tais decisões, e, como vem sendo julgadas após a recente decisão do Supremo Tribunal Federal em sede de repercussão geral. Foi utilizado o método dedutivo, com consulta às doutrinas, jurisprudências e sítios eletrônicos.
\end{abstract}

PALAVRAS-CHAVE: Execução judicial; Legitimidade ativa; Tribunal de Contas.

\section{ABSTRACT}

This study aimed to analyze the history and the question of the recent jurisprudential understanding of change, about the active legitimacy for judicial enforcement of the

\footnotetext{
1 Graduada em Direito pelo Centro Universitário Luterano de Palmas - CEULP ULBRA. Advogada. Servidora pública, e Pós Graduada em Direito e Processo Constitucional pela Universidade Federal do Tocantins - UFT.
} 
judgments of the Audit Office, within the historical perspective, constitutional doctrine and jurisprudence on the decision ARE 823.347 RG/MA, when the recognition of general repercussion, handed down by the Supreme Court. To reach the proposed objective, there will be a review of all historical context of the creation of the Court of Auditors by the enactment of $\mathrm{CRFB} / 88$. We will seek to understand what are the criteria used by the Audit Court, to pronounce decisions (judgments) in everyday practice on the subject. The legal nature and effectiveness of these decisions, and its applicability in the particular legal context will be lifted. In the end, the controversy caused by different interpretations assigned to constitutional provisions will be discussed, and ultimately will be made analysis about the active legitimacy, if the Brazilian Government Agency for Law Enforcement and Prosecution of Crimes has active legitimacy or even the Court itself could have the power to enforce such decisions, and, as has been judged after the recent decision of the Supreme Court in general repercussion of thirst. We used method deductive, in consultation with the doctrines, jurisprudence and electronic sites.

KEY WORDS: Active legitimacy; Court of Auditors; Judicial execution;

\section{CONSIDERAÇÕES INICIAIS}

O presente trabalho visa analisar o histórico e a questão da mudança do entendimento jurisprudencial recente acerca da legitimidade ativa para execução judicial de acórdãos proferidos pelos Tribunais de Contas, sob a perspectiva histórica, constitucional, doutrinária e jurisprudencial dada ao tema.

Uma das questões a ser debatida será a polêmica decorrente de diferentes interpretações conferidas a dispositivos constitucionais, se o Ministério Público possui legitimidade ativa ou se até mesmo o próprio Tribunal de Contas poderia ter competência para executar as decisões, e, como se realmente ocorre na prática após a decisão recente do Supremo Tribunal Federal que se manifestou em sede de repercussão geral no julgamento ARE 823.347 RGMA.

Ao levantar o debate a respeito da legitimidade para execução dos acórdãos proferidos pelos Tribunais de Contas, deseja-se contribuir, mesmo que minimamente, com o Estado Democrático de Direito, vez que tal atividade fiscalizadora foi prevista constitucionalmente nos artigos 70 a 75 da Constituição da República Federativa do Brasil de 1988. Ademais, a resolução da polêmica é medida imprescindível para a eficácia, ressarcimento do erário público e no julgamento dos 
processos que possuem correlação com o tema e que, por não raras vezes, restam obstados por discussões oriundas da ausência de posicionamento definitivo.

A metodologia utilizada na presente pesquisa pauta-se em pesquisa bibliográfica, histórica e jurisprudencial (emanada do Supremo Tribunal Federal e Superior Tribunal de Justiça), bem como em análise das normas constitucionais e infraconstitucionais a respeito da legitimidade para execução dos acórdãos proferidos pelos Tribunais de Contas.

Para tanto, far-se-á um breve histórico do Tribunal de Contas dentro das Constituições brasileiras até a Constituição da República Federativa do Brasil de 1988. Em seguida, o Capítulo 3 tratará sobre a natureza jurídica e eficácia das decisões proferidas pelos Tribunais de Contas.

E, no final, apresentará a execução das decisões proferidas pelos Tribunais de Contas e as mudanças recentes do entendimento jurisprudencial acerca da legitimidade ativa, proferida pelo Supremo Tribunal Federal no final do ano de 2014, no julgamento em sede de repercussão geral do ARE 823.347 RGMA.

\section{BREVE HISTÓRICO DO TRIBUNAL DE CONTAS NAS CONSTITUIÇÕES BRASILEIRAS}

De acordo com o Portal do Tribunal de Contas da união (BRASIL, 2016), a primeira iniciativa para criação do Tribunal de Contas no Brasil ocorreu em 23 de junho de 1826, através da iniciativa de Felisberto Caldeira Brandt, Visconde de Barbacena e José Inácio Borges que apresentaram no Senado do Império um projeto de lei que previa a criação de tal órgão.

Afirma Cheker (2009, p.24) que esse projeto de lei visava à organização da administração geral do Estado, onde o Tesouro nacional seria de responsabilidade de um administrador geral, sujeito a um Tribunal de Revisão de Contas, o qual deveria ter seu regime próprio.

Em outubro de 1831, editou-se a Lei $n^{\circ} 657$, que criou o Tribunal do Tesouro Público Nacional, que trouxe as seguintes atribuições, segundo SIQUEIRA (1999, p. 151):

Administrar a receita e a despesa pública, a contabilidade e os bens nacionais, receber a prestação de contas anuais de todas as 
repartições públicas, analisar os empréstimos e a legislação fazendária, inspecionar as repartições da fazenda, ainda que dependentes de outros Ministérios e demitir funcionários públicos considerados inidôneos e inabilitados à ocupação dos cargos.

Esta lei estava direcionada à Corte e à Província do Rio de Janeiro, sendo a primeira Lei orçamentária do Brasil, lembrando que na época o Brasil tinha apenas leis coloniais.

As discussões acerca da criação do Tribunal de Contas duraram quase meio século, enquanto uns defendiam sua necessidade e autonomia, outra corrente entendia que as contas públicas podiam continuar sendo controladas por aqueles mesmos que as realizavam. (ARAÚJO, 2010, p. 123)

Todavia, segundo o Portal do Tribunal de Contas da União (BRASIL, 2016) somente após a queda do Império, através do Decreto 966-A de 07 de novembro de 1890, por iniciativa do Ministro da Fazenda na época, Sr. Rui Barbosa, foi criado o primeiro Tribunal de Contas do Brasil.

Destaca-se as principais palavras históricas do Ministro Rui Barbosa, segundo Fernandes (2009, p. 653):

A medida que vem propor-vos é a criação de um Tribunal de Contas, corpo de magistratura intermediária à Administração e à Legislatura que, colocado em posição autônoma, com atribuições de revisão e julgamento, cercado de garantias contra quaisquer ameaças, possa exercer as suas funções vitais no organismo constitucional, sem risco de converter-se em instituição de ornato aparatoso e inútil (...)(FERNANDES, 2009, p. 653)

A primeira Constituição do Brasil a prever o Tribunal de Contas foi a de 1891, ainda por influência de Rui Barbosa, que conferiu as atribuições para liquidar e verificar a legalidade das contas das receitas e despesas antes de serem prestadas ao Congresso Nacional. Vejamos o Artigo 89 da Constituição de 1891(BRASIL, 2015):

Art. 89 - É instituído um Tribunal de Contas para liquidar as contas da receita e despesa e verificar a sua legalidade, antes de serem prestadas ao Congresso. Os membros deste Tribunal serão nomeados pelo Presidente da República com aprovação do Senado, e somente perderão os seus lugares por sentença.

Mas somente em 17 de janeiro de 1893, com a ajuda do Ministro da Fazenda 
do governo de Floriano Peixoto, Serzedello Corrêa, que ocorreu a instalação do Tribunal de Contas que tinha competência para exame, revisão e julgamento de todas as operações relacionadas com as receitas e despesas da União. (BRASIL, 2016)

Na opinião de LIMA (1990, p. 05) a constituição de 1934 do Brasil trouxe um verdadeiro avanço nas atribuições do Tribunal de Contas, inclusive a de proceder ao acompanhamento da execução orçamentária, o registro prévio das despesas e dos contratos, o julgamento das contas responsáveis por bens e dinheiros públicos, assim como a apresentação de parecer prévio sobre as contas do Presidente da República do Brasil para posterior encaminhamento à Câmara dos Deputados.

Em outras Constituições como na de 1937, a competência do Tribunal de Contas foi mantida, com exceção do oferecimento de parecer prévio sobre as contas do Presidente da República. (MIRANDA, 1970, p. 248)

A Constituição de 1946, após oito anos de ditadura, dedicou uma atenção especial ao Legislativo, dividindo o Congresso Nacional em duas casas, o Tribunal de Contas recuperou sua força e independência, e, acrescentou mais uma função de julgar a legalidade da concessão da aposentadoria, reformas e pensões, segundo informações do portal do Tribunal de Contas da União (BRASIL, 2016).

Infelizmente, na visão de LIMA (1990, p.05) não se pode dizer o mesmo da Constituição do Brasil de 1967 que excluiu da competência do Tribunal de Contas de examinar e julgar previamente os atos e contratos geradores de despesas da verba pública e eliminou também a atribuição para julgamento da legalidade de concessões de aposentadoria, reformas e pensões.

Vale destacar, que a denominação Tribunal de Contas da União surgiu dentro da reforma da Constituição de 1967, autorizando também a criação de Tribunais de Contas Municipais para aqueles municípios que tivessem população superior a dois milhões de habitantes e renda tributária superior a quinhentos milhões de cruzeiros novos, nascendo assim o Tribunal de Contas de São Paulo e Rio de Janeiro, existentes até hoje. 


\subsection{O TRIBUNAL DE CONTAS A PARTIR DA CONSTITUIÇÃO DA REPÚBLICA FEDERATIVA DO BRASIL DE 1988}

Com a promulgação da Constituição da República Federativa do Brasil de 1988 (CRFB/88) houve o fortalecimento da instituição do Tribunal de Contas com sua jurisdição e competência ampliadas, recebendo funções de fiscalização contábil, financeira, orçamentária, operacional e patrimonial da União e das entidades da administração direta e indireta. (ARAÚJO, 2010. P. 133)

Vejam-se pequenos trechos do artigo 71 da Constituição de 1988 (BRASIL, 2015):

Art. 71. O controle externo, a cargo do Congresso Nacional, será exercido com o auxílio do Tribunal de Contas da União, ao qual compete:

I - apreciar as contas prestadas anualmente pelo Presidente da República, mediante parecer prévio que deverá ser elaborado em sessenta dias a contar de seu recebimento;

II - julgar as contas dos administradores e demais responsáveis por dinheiros, bens e valores públicos da administração direta e indireta, incluídas as fundações e sociedades instituídas e mantidas pelo Poder Público federal, e as contas daqueles que derem causa a perda, extravio ou outra irregularidade de que resulte prejuízo ao erário público; [...]

A CRFB/88 pela primeira vez mencionou o Ministério Público como atuante junto ao Tribunal de Contas da União, abrigando-o em dispositivo isolado em seu artigo 130.

Quanto à composição do Tribunal, a nova Constituição não trouxe alterações, ficando mantido o número de nove ministros, alterando somente os critérios de nomeação. Pelas novas regras, os Ministros passaram a ser escolhidos um terço pelo Presidente da República e dois terços pelo Congresso Nacional, quanto ao terço do Presidente, apenas a terça parte ficaria a critério exclusivo do mesmo, recaindo as demais nomeações alternadamente entre auditores e membros do Ministério Público junto ao Tribunal, por ele indicados em lista tríplice, segundo critérios de antiguidade e merecimento. (BRASIL, 1999)

No que diz respeito a garantias, prerrogativas e impedimentos, ficaram os membros do Tribunal de Contas da União equiparados aos Ministros do Superior Tribunal de Justiça.

A principal essência da CRFB/88 em relação ao Tribunal de Contas foi buscar a eficiência na atuação administrativa para controle dos gastos públicos, pautandose pelos princípios da legalidade e moralidade, buscando sempre aferir a probidade 
dos gestores públicos e dos particulares que mantêm relações comerciais com a Administração pública.

Constata-se pela nova Constituição, em resumo, que ao Tribunal de Contas compete, sem ressalvas, julgar as contas de todo o universo de órgãos da administração pública Direta e das entidades da Administração Indireta, controlando, de forma irrestrita, todos os gastos oriundos de recursos públicos, em seus aspectos contábil, financeiro, orçamentário, operacional e patrimonial.

A inclusão pela primeira vez, do controle operacional, permite a avaliação do desempenho da gestão pública, não somente da legalidade, legitimidade e probidade dos seus atos, bem como da economicidade dos valores aplicados, comparando os gastos efetivados e resultados colhidos. (BRASIL, 1999)

A CRFB/88 (BRASIL, 2015) trouxe o direito e a responsabilidade de toda a sociedade de exercer o controle dos gastos públicos ao trazer em seu artigo 74, §2 que "Qualquer cidadão, partido político, associação ou sindicato é parte legítima para, na forma da lei, denunciar irregularidades ou ilegalidades perante o Tribunal de Contas da União".

Também elencou no artigo 71, inciso IV, a iniciativa do Tribunal de Contas da União de realizar inspeções, auditorias e levantamentos, sobre as várias modalidades de controle nas unidades administrativas dos poderes da União e demais entidades e organizações públicas. Também manteve no inciso I do artigo 70, a prática de parecer prévio sobre as contas anuais do Presidente da República, a serem julgadas pelo Congresso Nacional. (BRASIL, 2015)

Apesar da autonomia diante dos poderes constituídos, a CRFB/88 no caput do artigo 71 definiu o Tribunal de Contas da União como órgão auxiliar do Congresso Nacional, não implicando em subordinação ao Poder Legislativo e sim auxílio, não estando subordinado a nenhum outro Poder.

Sucintamente, integram a estrutura do Tribunal de Contas da União: o órgão de deliberativo, o Ministério Público especial, órgãos técnicos, órgãos de estrutura de apoio administrativos e uma unidade de treinamento denominada Instituto Serzedello Corrêa.

Com relação aos Estados membros estes devem, obrigatoriamente, adotar Tribunal de contas e estão obrigados a observar, em suas linhas básicas o modelo federal de fiscalização orçamentária e financeira, no qual incluem as normas institucionais da União sobre a estrutura, prerrogativas, competência, organização e 
funcionamento de seu Tribunal de Contas. Por força do princípio da simetria, as regras do Tribunal de Contas da União (TCU) são aplicadas, no que couber, aos Tribunais de Contas dos Estados (TCEs), conforme determina o artigo 75 da CF/88. (BRASIL, 2015)

Competirá as Constituições Estaduais disporem sobre os Tribunais de Contas, o qual adiantou o constituinte, devem ser integrados necessariamente por sete conselheiros, guardando conformidade com o modelo federal, exceto em relação aos órgãos técnicos, que se limitam à respectiva área de jurisdição.

A título exemplificativo indica-se a base legal do Tribunal de Contas do Estado do Tocantins que foi Criado pela Lei $n^{\circ} 230$, de 18 de dezembro de 1990, conforme site oficial da Assembléia Legislativa do Estado do Tocantins (BRASIL, 2015).

\section{NATUREZA JURÍDICA E EFICÁCIA DAS DECISÕES PROFERIDAS PELOS TRIBUNAIS DE CONTAS}

A CRFB/88 inaugurou o dever de organização e o sistema de ação de controle, dividindo-o em dois: o controle interno e o controle externo. (BRASIL, 2015)

De acordo com Fernandes (2008, p. 658) o controle interno, vivencia a intimidade da organização para um acompanhamento mais eficaz realizado pelo próprio órgão controlado; já o controle externo é vivenciado pela estrutura independente com poder constritivo para efetivar recomendações de acatamento compulsório, realizado por diversas formas e pelo Poder Legislativo com o auxílio do Tribunal de Contas, que tem como incumbência precípua executar a fiscalização financeira e orçamentária da aplicação dos recursos da Administração pública, com base legal nos artigo 70 a 75 da CRFB/88.

Afirma Castro (2000, p. 57) que as atribuições dos TCEs não podem sofrer qualquer ação inibitória por parte dos poderes estatais em sua atividade fiscalizatória:

Visam permitir o pleno exercício da função fiscalizatória em face da administração da receita e da despesa pública, que são exercidas pelos três Poderes da República. Com efeito, é da incumbência insubtraível do Tribunal de Contas fiscalizar o Executivo, o Judiciário e o próprio Legislativo, de cuja estrutura é integrante. 
Os TCEs têm autonomia administrativa, financeira e servidores com regimento interno próprio, conforme determina a CRFB/88 em seu artigo 73, além de atribuições bem definidas, com poderes específicos, inclusive para sustar a execução de contratos, constituindo-se como um importante instrumento para o controle da administração pública. (BRASIL, 2015)

A função do julgamento de contas dos administradores e demais responsáveis por dinheiro, bens e valores públicos da administração direta e indireta exercida pelos Tribunais de Contas se encontra previsto no artigo 71, III da CRFB/88 (BRASIL, 2015).

De acordo com TORRES (1191, p. 37) parte da doutrina defende que as decisões do Tribunal de Contas exercem uma função jurisdicional, não pelo emprego da palavra "julgamento" no texto Constitucional, mas sim pelo sentido definitivo da manifestação da Corte. Reafirmando que o Tribunal de Contas exerce alguns atos típicos da função jurisdicional em sentido material, uma vez que julga as contas dos administradores e responsáveis com todos os requisitos materiais da jurisdição: independência, imparcialidade, igualdade processual, ampla defesa, produção plena das provas e direito a recurso.

Todavia, prepondera na jurisprudência e doutrina majoritária a natureza jurídica administrativa das decisões proferidas pelos Tribunais de Contas , com fulcro no artigo $5^{\circ}$, inciso $\mathrm{XXXV}$, da $\mathrm{CRFB} / 88$, ainda que relativo à apreciação de contas, esta poderá ser submetida ao exame do poder Judiciário, se o interessado considerar que houve lesão ao seu direito, não havendo definitividade ou imutabilidade de seus efeitos, que são inerentes ao Poder Judiciário que segundo Silva (1998, p. 112):

O Tribunal de Contas é um órgão técnico, não jurisdicional. Julgar contas ou da legalidade dos atos, para registros, é manifestamente atribuição de caráter técnico (...). É, portanto, um controle de natureza política, no Brasil, mas sujeito à prévia apreciação técnicoadministrativa do Tribunal de Contas competente, que, assim, se apresenta como órgão técnico, e suas decisões são administrativas, não jurisdicionais.

Desta forma, o controle externo é exercido pelo Congresso Nacional, com auxílio do TCU, e pelo princípio da simetria, as Assembléias Legislativas com auxilio dos TCE's, de acordo com o artigo 71 da CRFB/88 (BRASIL, 2015) poderão: 
(...) aplicar aos responsáveis, em caso de ilegalidade de despesa ou irregularidade de contas, as sanções previstas em lei, que estabelecerá, entre outras cominações, multa proporcional ao dano causado ao erário.

Afirma Costa Júnior (2001, p. 45) que as decisões condenatórias proferidas pelo Tribunal de Contas são aquelas em que o Tribunal julga as contas dos responsáveis como irregulares, imputando-lhe um débito ou cominando-lhe uma multa. Ainda segundo ele, o Tribunal de Contas imputa o débito ao gestor ou Ihe aplica a multa, proferindo uma decisão de caráter eminentemente condenatório.

De acordo com Chaves (2009, p. 55) impede destacar que o débito e a multa possuem natureza jurídica distinta, apesar de serem exemplos expressos de pecúnias, o débito possui natureza de responsabilização civil pelo prejuízo causado ao patrimônio público e a multa possui natureza de sanção.

O débito seria a lesão quantificada em termos monetários, cuja tramitação visa recompor o dano ao erário lesado, fazendo que retorne aos cofres públicos esse dano sofrido. Já a multa seria uma sanção de natureza pecuniária que deve ser recolhida ao patrimônio do ente federado ao qual pertença o Tribunal de Contas sancionador. (CHAVES, 2009, p. 55)

Assim, os TCE's poderão aplicar multas ou determinar que o gestor faça o ressarcimento de valores ao erário. Estas decisões das Cortes se materializam através de um acórdão.

Com relação à eficácia, esses acórdãos serão títulos executivos extrajudiciais, nos termos do artigo $\S 3^{\circ}$ do artigo 71 da CRFB/88 (BRASIL, 20015) que diz que "As decisões do Tribunal de que resulte imputação de débito ou multa terão eficácia de título executivo".

A decisão proferida pelo Tribunal de Contas não precisa ser inscrita em dívida ativa. Pois, a finalidade de se inscrever o débito na dívida ativa é gerar uma certidão de dívida ativa, que seria indispensável para o ajuizamento da execução, mas como o acórdão proferido pelo Tribunal de Contas se trata de um título extrajudicial por força do art. $71, \S 3^{\circ}$ da CRFB/88 (BRASIL, 2015) não há essa necessidade do débito ser inscrito em dívida ativa.

Da mesma forma, como se executa o próprio acórdão proferido pelo Tribunal de Contas, não se faz a execução por meio do procedimento utilizado pela execução 
fiscal e sim pela execução civil de titulo extrajudicial, seguindo as regras dos artigos 556 e seguintes do Código de Processo Civil (BRASIL, 2016).

Logo, Fernandes (2008, p. 381) ensina que os acórdãos podem ser executados por meio de uma ação de execução de titulo extrajudicial, onde deverão constar, de forma precisa, o agente responsável, o valor do dano ou da multa, a data a partir que correrão os juros e atualização, número do processo com data e o beneficiário do título, a fim de que goze dos atributos da certeza e liquidez.

\section{DA EXECUÇÃO JUDICIAL DOS ACÓRDÃOS (DECISÕES) PROFERIDOS PELOS TRIBUNAIS DE CONTAS E DO ENTENDIMENTO DO STF ACERCA DA LEGITIMIDADE ATIVA}

O agente responsável pelo Tribunal de Contas que não pagar o valor voluntariamente na via administrativa, será necessária a execução judicial do acórdão proferido.

Fernandes (2008, p. 410) afirma que o pressuposto material da execução para ser forçada é a exequibilidade da pretensão, ou seja, a definitividade da decisão, se esgotando todos os recursos ou a preclusão da possibilidade de impetração na área administrativa, ou, então, que o mesmo esteja pendente de recursos sem efeito suspensivo.

Na opinião de Fernandes (2008, p. 411) após o prazo dos recursos ou do julgamento dos mesmos, cabe ao Tribunal de Contas, remeter ao órgão competente para que promova a execução do julgado, podendo ser remetida e promovida por intermédio do Ministério Público especial, que atua junto aos tribunais, mas o assunto não é pacífico, em virtude de existirem Tribunais de Contas que promovem tal remessa diretamente.

No tocante ao mérito da legitimidade ativa para a execução, a Primeira Seção do Superior Tribunal de Justiça (BRASIL, STJ, 2016) pacificou o tema no ano de 2009 no sentido de que o Ministério Público tinha legitimidade para promover a execução do acórdão decorrente de decisão do Tribunal de contas, ainda que em caráter excepcional, nas hipóteses que o sistema de legitimação ordinária da defesa do erário falhasse. Veja a ementa do julgado proferida pelo Superior Tribunal de Justiça (BRASIL, STJ, 2016): 
ADMINISTRATIVO E PROCESSUAL CIVIL. AGRAVO REGIMENTAL. AÇÃO CIVIL PÚBLICA. EXECUÇÃO DE TÍTULO EXECUTIVO EXTRAJUDICIAL. CONDENAÇÃO PELO TRIBUNAL DE CONTAS DA UNIÃO. MINISTÉRIO PÚBLICO FEDERAL. LEGITIMIDADE. SITUAÇÃO EXCEPCIONAL CONFIGURADA. FALHA DO SISTEMA ORDINÁRIO DE REPRESENTAÇÃO E DEFESA DO ERÁRIO. 1. Pacificou-se na Primeira Seção desta Corte Superior o entendimento segundo o qual o Ministério Público tem legitimidade para promover execução de título executivo extrajudicial decorrente de decisão do Tribunal de Contas, ainda que em caráter excepcional - i.e., quando o sistema de legitimação ordinária de defesa do erário falha (v. REsp 1.119.377/SP, Rel. Min. Humberto Martins, Primeira Seção, j. 26.8.2009). 2. No caso dos autos, o processo que levou à formação do título executivo é de 1996 e a presente execução foi ajuizada em 2001, o que faz concluir que está configurada a falha do representante e/ou do advogado público. 3. Além disso, sob pena de malversação da distribuição constitucional de competências no âmbito dos Tribunais Superiores e do Supremo Tribunal Federal, não compete ao Superior Tribunal de Justiça a manifestação sobre a alegada ofensa a dispositivos constitucionais. 4. Agravo regimental não provido.

O Relator do recurso Ministro Mauro Campbell Marques (BRASIL, STJ, 2016) fundamentava seu posicionamento no dispositivo constitucional elencado no artigo 129 e na Súmula 329 do STJ, que afirmava que "estando em risco à integridade do patrimônio público, o Ministério Público (MP) estará legitimado a agir”.

Para ele, a CRFB/88 ao proibir que o MP exercesse a advocacia pública em seu artigo 129, IX, o fazia com a finalidade para que desempenhasse melhor suas funções institucionais, sem se preocupar com o interesse público secundário, cargo esse das procuradorias. Mas, na falha da defesa do patrimônio público, quando a legitimação ordinária falhar, surgiria à possibilidade do MP, atuar como legitimado extraordinário, e assim nasceria sua legitimidade ativa para executar as decisões proferidas pelos Tribunais de Contas. (BRASIL, STJ, 2016)

Afirmava ainda o Relator Ministro Mauro Campbell Marques (BRASIL, STJ, 2016) que "O patrimônio público, como dito, pertence à sociedade, não as pessoas jurídicas de direito público". Durante vários anos esse foi o entendimento do STJ, como se observa em diversos julgados, a exemplo do AgRg no REsp 1230313/MG, do REsp 1189576/MG, e do REsp 736484/RJ.

Entretanto, o Supremo Tribunal Federal (STF) em recente julgado em sede de repercussão geral no final do ano de 2014, estabeleceu que a execução do acórdão 
proferido pelo Tribunal de Contas somente poderá ser proposta pelo ente público beneficiário da condenação, bem como expressamente afastou a legitimidade ativa do Ministério Público para a referida execução. Colacionamos a ementa do julgado proferido pelo Supremo Tribunal Federal (BRASIL, STF, 2016):

Recurso extraordinário com agravo. Repercussão geral da questão constitucional reconhecida. Reafirmação de jurisprudência. 2. Direito Constitucional e Direito Processual Civil. Execução das decisões de condenação patrimonial proferidas pelos Tribunais de Contas. Legitimidade para propositura da ação executiva pelo ente público beneficiário. 3. Ilegitimidade ativa do Ministério Público, atuante ou não junto às Cortes de Contas, seja federal, seja estadual. Recurso não provido.

Para o Relator Ministro Gilmar Mendes (BRASIL, STF, 2016), estaria ausente a legitimidade ativa do MP, por não se poder ampliar a interpretação do artigo 129 da CRFB/88, logo, a situação não se enquadraria na hipótese de proteção ao patrimônio público ou de outros interesses difusos e coletivos.

Depois desse julgado, diversos outros foram proferidos pelo $\mathrm{STJ}^{2}$ e $\mathrm{STF}^{3}$ já no ano de 2015 reafirmando que a propositura da ação executiva seria apenas do ente público beneficiário, sendo ilegítimo o Ministério Público, atuante ou não junto às Cortes de Contas, seja federal ou estadual.

A legitimidade para execução dos acórdãos proferidos pelos Tribunais de Contas na atualidade, seria do ente público prejudicado, aquele que teve seu patrimônio lesado, a exemplo de prestação de contas de determinado Município que utilizou de recursos federais repassados mediante convênio, a competência da fiscalização é do Tribunal de Contas da União, a legitimidade ativa para executar o acórdão é da própria União, ente lesado, e o sujeito passivo é o agente responsável, no caso o Prefeito.

Com relação às demais esferas Fernandes (2008, p.415) afirma:

Nos Estados, no Distrito Federal e nos Municípios, quando a condenação pelos Tribunais de Contas forem em favor das respectivas administrações diretas, a respectiva procuradoria deverá ser encarregada da execução forçada da deliberação.

\footnotetext{
${ }^{2}$ AgRg no REsp 1518430 / MA ; REsp 1464226 / MA.

3 ARE 791577 AgR / MA.
} 
Com relação à administração indireta, caberá ao órgão, que representa judicialmente os interesses da respectiva pessoa jurídica, intentar o processo de execução.

Destaca-se que de acordo com a sistemática vigente, a legitimidade ativa para a execução judicial dos acórdãos proferidos não compete aos Tribunais de Contas e nem ao Ministério Público, mas sim, aos órgãos competentes para a representação judicial do ente Federado ou da entidade da Administração Indireta.

Desta forma, no caso de decisões condenatórias proferidas pelo TCU, se o cofre lesado foi o da União, o ajuizamento incumbe ao órgão responsável por sua representação judicial, à Advocacia Geral da União. No caso de decisões condenatórias proferidas pelos TCEs e TCMs, se o cofre lesado for o ente estadual, cabe aos Procuradores do Estado o ajuizamento da ação de execução, mas, se o cofre lesado for do município, a capacidade postulatória pertence aos Procuradores dos Municípios, onde houver, ou a escritórios de advocacia privado contratados pelo Poder Público.

Essas regras se aplicam apenas a imputação de débito, no caso das multas, seu pagamento reverterá diretamente aos cofres do ente federado, razão pela qual sua execução compete à AGU quando forem aplicadas pelo TCU e aos Procuradores do Estado, quando aplicada pelos TCEs e TCMs.

\section{CONSIDERAÇÕES FINAIS}

Conforme restou demonstrado no presente trabalho, a Instituição Tribunal de Contas conviveu com constantes impasses em seu contexto histórico até firmar sua competência e atribuições na Constituição da República Federativa do Brasil de 1988.

Apesar dos esforços empreendidos na estruturação deste órgão fiscalizador na Constituição de 1988, inclusive atribuindo eficácia de título executivo às decisões proferidas pelos Tribunais de Contas, faltou conceder poderes para que esta Instituição tivesse condições de efetivar as suas próprias decisões, tendo em vista que não podem propor diretamente a ação de execução judicial.

Antes de 2015, a jurisprudência dos Tribunais Superiores admitia a legitimidade extraordinária do Ministério Público Comum para propor a execução judicial das decisões proferidas pelos Tribunais de Contas, quando as Procuradorias 
(legitimado ordinário) não as faziam, o que acabava fortalecendo bastante os acórdãos proferidos pelo Tribunal.

Após a recente decisão do Supremo Tribunal Federal no ARE 823.347 RGMA, o Ministério Público perdeu esta legitimidade, mesmo em caráter excepcional, enfraquecendo a Instituição, pois o agente legitimado atualmente é o próprio ente lesado (AGU, Procuradorias Estaduais, Procuradorias Municipais ou advogados contratos).

Assim, torna-se compreensível a razão pela quais muitas decisões dos Tribunais de Contas não chegam a serem cumpridas, pois é comum encontrar situações em que a pessoa condenada pelo Tribunal de Contas também é o agente público responsável pela propositura da ação judicial de execução, ou são pessoas muito próximas, especialmente em municípios pequenos como aqueles encontrados em nosso Estado do Tocantins.

Seria imparcial se houvesse a possibilidade dos Tribunais de Contas executarem diretamente seus acórdãos por intermédio do Ministério Público que atua junto a ele, sem a intermediação dos órgãos executores, a exemplo da Advocacia Geral da União e das Procuradorias Estaduais, que já foi objeto de questionamento ao Supremo Tribunal Federal.

Nesse contexto, importante registrar que pequena parte da doutrina defendem o reconhecimento da capacidade postulatória dos Tribunais de Contas, em razão da inexistência de previsão proibitiva no ordenamento jurídico vigente.

O fato seria que para eventual atribuição de capacidade postulatória ativa aos Tribunais de Contas para executar judicialmente suas decisões, far-se-iam necessários estudos adicionais a uma reestruturação na forma de atuação de tais órgãos para que tivesse maior efetividade nas suas atribuições constitucionais.

Desta forma, devemos sempre relembrar e não perdermos de vista à visão externada pelo defensor da criação da instituição Tribunal de Contas, o Ministro da Fazenda Rui Barbosa, no sentido de proteger este Tribunal para que se fortaleça cada dia mais, aumentando suas garantias e proteções constitucionais contra qualquer ameaça na defesa ao erário público. 


\section{REFERÊNCIAS}

ALVARES. Elcio. Efeito positivo. Revista do Tribunal de Contas da União. Brasília, v. 27, n. 70, p. 37- 38, 1996.

ARAÚJO, Júlio Cesar Manhães de. Controle da Atividade Administrativa pelo

Tribunal de Contas na Constituição de 1988. Curitiba: Juruá, 2010.p.123.

BRASIL. Tribunal de Contas da União. Breve Histórico. Disponível em: $<$ http://portal3.tcu.gov.br/portal/page/portal/TCU/institucional/conheca tcu/historia $>$ Acesso em: 19 de jan. 2016.

. Assembleia Legislativa do Tocantins. Lei $\mathbf{n}^{\circ} \mathbf{2 3 0}$, de 18 de dezembro de 1990. Disponível em: <www.al.to.gov.br/arquivo/6490>. Acesso em: 04.ago.2015.

. Constituição de 1891. Disponível em:

<http://www.planalto.gov.br/ccivil 03/constituicao/constituica091.htm >.Acesso em: 02 dez. 2015.

. Constituição da República Federativa do Brasil de 1988. Disponível em: $<$ http://www.planalto.gov.br/ccivil 03/Constituicao/Constituicao.htm >. Acesso em: 09 dez. 2015.

. Portal do Tribunal de Contas da União. Breve Histórico. Disponível em: <http://portal3.tcu.gov.br/portal/page/portal/TCU/institucional/conheca tcu/historia > Acesso em: 02 jan. 2016.

. Superior Tribunal de Justiça. REsp: 736484 RJ 2005/0042571-0, Agravante: Sociedade de ensino Superior Nova Iguaçu e outro, Agravado: Ministério Público Federal. Relator: Ministro MAURO CAMPBELL MARQUES, Data de Julgamento: 03/11/2009, T2 - SEGUNDA TURMA. Data de Publicação: DJe 13/11/2009.

Disponível em: <http://stj.jusbrasil.com.br/jurisprudencia/5682678/agravo-regimentalno-recurso-especial-agrg-no-resp-736484-ri-2005-0042571-0/inteiro-teor-11840979> Acesso em: 09 jun. 2016.

. Supremo Tribunal Federal. ARE 823.347 RGMA, Tribunal Pleno. Recorrente: Ministério Público do Estado do Maranhão, Recorrido: Washington Luiz Silva Plácio. Rel. Min. GILMAR MENDES, DJe de 28.10.2014. Disponível em: $<$ http://redir.stf.jus.br/paginadorpub/paginador.jsp?docTP=TP\&doclD=7044506> Acesso em: 09 jun. 2016.

. Tribunal de Contas da União. Prêmio Serzedello Corrêa 1998:

Monografias Vencedoras. Brasília: TCU-Instituto Serzedello Corrêa, 1999. p.128. CASTRO, Carlos Roberto Siqueira. A atuação do Tribunal de Contas em face da separação de Poderes do Estado. Revista de Direito Constitucional e Internacional. a. 8, n. 31, p. 57-73, abr./jun. 2000. P.57. 
CHAVES, Francisco Eduardo Carrilho. Controle Externo da Gestão Pública. 2ed. Niterói: Impetus, 2009. P. 55.

COSTA JÚNIOR, Eduardo Caroneda. As funções jurisdicional e opinativa do Tribunal de Contas. Revista do Tribunal de Contas do Estado de Minas Gerais, Belo Horizonte, ano XIX, n. 2, p.45-115, 2001.

CHEKER, Monique. Ministério Público junto ao Tribunal de Contas. Belo Horizonte: Fórum, 2009. p. 24.

FERNANDES, Jorge Ulysses Jacoby. Tribunais de Contas do Brasil: jurisdição e competência. Belo Horizonte: Fórum, 2009. p. 653.

LIMA, Alfredo Guimarães Oliveira. Tribunal de Contas da União. Brasília: Centro Gráfico do Senado Federal, 1990.p.05.

MIRANDA, Francisco Cavalcanti Pontes de. Comentários à Constituição de 1967: com a EC n.01, de 1969. São Paulo: RT, 1970, t.III, p.248.

SILVA, José Afonso da. Curso de Direito Constitucional Positivo. 16 ed. São Paulo: Malheiros Editores, 1998.p.112.

SIQUEIRA, Bernardo Rocha. O Tribunal de Contas da União de Ontem e de Hoje.In: Prêmio Serzedello Corrêa 1998: monografias Vencedoras. Brasília: TCU Instituto Serzedello Corrêa, 1999, p. 151.

TORRES, Ricardo Lobo. O Tribunal de Contas e o controle da legalidade, economicidade e legitimidade. Revista do Tribunal de Contas do Estado do Rio de Janeiro. Rio de Janeiro, v. 13, n. 22, jul. 1991.p.37. 